\title{
Elementos ideológicos en las unidades fraseológicas con la palabra mujer dentro del lema mujer en el Diccionario académico de los siglos XVIII y XIX
}

\author{
Ideological elements in the phraseological units with the word woman in the Academic \\ Dictionary of the XVIIIth and XIXth centuries
}

\author{
Amparo García Ramón
}

\begin{abstract}
Resumen
Este trabajo analiza el sesgo ideológico en lo que respecta a cuestiones de género en las unidades fraseológicas con la palabra mujer que aparecen dentro del lema mujer en las diferentes ediciones del Diccionario publicado por la Real Academia Española durante los siglos XVIII y XIX. Se analiza, por una parte, el contenido ideológico presente en las unidades fraseológicas en sí mismas. Por otra, se describen los fenómenos enunciativos presentes en las definiciones de las unidades fraseológicas, que dan cuenta de la subjetividad presente no solo en las entradas del diccionario, sino también en el discurso de los propios académicos. Para abordar la primera cuestión, se presenta una tipología de las diferentes unidades fraseológicas según criterios sintáctico-semánticos: dicha categorización pone de manifiesto el tipo de rol otorgado a la mujer en las unidades fraseológicas, teniendo en cuenta, por ejemplo, el tipo de elementos con que se coordina el sustantivo mujer/mujeres. Para abordar la segunda, se analiza la subjetividad lingüística en las definiciones atendiendo a los diferentes momentos en que los académicos dejan ver su propia voz en relación con cuestiones prescriptivas y morales.
\end{abstract}

Palabras clave: diccionario, ideología, unidades fraseológicas, género, mujer

\begin{abstract}
This paper explores ideological elements regarding gender in phraseological units with the word mujer('woman') in the different editions of the dictionarypublished by Real Academia Española during the $18^{\text {th }}$ and the $19^{\text {th }}$ centuries. First, the ideological content in the phraseological units themselves is analyzed. Second, phenomena related to subjectivity in the definitions are analyzed: this evidences subjectivity not only in the different phraseological units presented in the dictionary, but also in the discourse of the academics. In order to approach the first issue, a typology of the different phraseological units according to their syntactic-semantic properties is provided: this categorization shows the type of role given to women in the phraseological units, based, for example, on the types of elements with which the noun woman/womencombines. In order to consider the second issue, linguistic subjectivity is analyzed through a description of the moments in which the academics let their own voice appear in the definitions, in relation to moral and prescriptive issues.
\end{abstract}

Keywords: dictionaries, ideology, phraseological units, gender, mujer

Amparo García Ramón, Universitat de València, Amparo.Garcia-Ramon@uv.es

Recibido: diciembre 2016 / Aceptado: abril 2017

DOI 10.17710/tep.2017.3.2.2garciaramon

García Ramón, A. (2018). Elementos ideológicos en las unidades fraseológicas con la palabra mujer dentro del lema mujer en el Diccionario académico de los siglosXVIII y XIX .Textos en Proceso 3(2), 144-165 


\section{Introducción}

Se dice que el diccionario es el libro de todas las palabras y, en ese sentido, es notario: da fe de la realidad lingüística. Pero el diccionario -especialmente el académico, por su función normativa y su elevado prestigio- también se erige como reglamento y es, por ello, legislador (Forgas Berdet, 2007). En su capítulo sobre "Las obras lexicográficas de la Academia", Ruhstaller (2003) señala el prestigio y la general aceptación de que goza la institución. Con respecto a la labor lexicográfica, el autor señala varios logros: por ejemplo, explica que, con la elección de citas, la Academia pretendió "emitir un juicio basado en criterios objetivos" (2003: 240). Sin embargo, pedir esa objetividad al Diccionario es quizá demasiado optimista cuando no directamente injusto-. Concretamente, con respecto a la inclusión y exclusión de unidades fraseológicas (esto es, unidades de significado relativamente fijado y no composicional, conmutables por diferentes tipos de unidades lingüísticas), en el "Prólogo" de la edición de 1726, se explica que se incluirán los refranes que "son mas moráles", puesto que "sería trabájo mui inútil expressar los que no tienen moralidád, y buen sentído".

En contraste con los estudios que defienden o alaban la neutralidad en la labor lexicográfica, se ha desarrollado en las últimas décadas el interés por detectar el contenido ideológico en los diccionarios. Los trabajos que se muestran más críticos a este respecto han tendido a centrarse especialmente en el diccionario académico, debido precisamente a su gran consideración social (Blecua Perdices, 1990; Forgas Berdet, 1999). Un grupo de estudiosos ha mostrado que, en los diccionarios actuales, se dan rasgos sintomáticos de una actitud discriminatoria hacia varios colectivos, por ejemplo, gitanos, mujeres o comunistas (ver, entre otros, Rodríguez Barcia y Ramallo, 2015), y ha prestado asesoramiento en la elaboración del DRAE de 2001 (Forgas Berdet y Herrera Rodrigo, 2000; Lledó Cunill, Calero Fernández y Forgas Berdet, 2004; Forgas Berdet, 2004, 2007) ${ }^{1}$. La ideología emerge, según estos trabajos, en lugares precisos del diccionario, como la selección de lemas, el género de las profesiones, la adscripción de marcas pragmáticas, la subjetividad en las definiciones, la elección de ejemplos o la explicación de etimologías (Forgas Berdet, 2007). Se han publicado asimismo estudios que revisan críticamente la labor lexicográfica de la Academia en general (ver, p. ej., la obra colectiva El dardo en la Academia, editada por Senz y

\footnotetext{
${ }^{1}$ Por ejemplo, este colectivo había sugerido, tras la petición de colaboración de la RAE, que en la edición de 2001 del diccionario se incluyeran marcas pragmáticas para los usos despectivos (p. ej., zorra) y que términos de difusión reciente (p. ej., sororidad) se incluyeran en la macroestructura.
} 
Alberte, 2011), así como trabajos que se centran en la elaboración de metodologías adecuadas para el análisis ideológico del discurso lexicográfico (Rodríguez Barcia, 2012) o volúmenes íntegramente dedicados a la subjetividad en el discurso lexicográfico (Rodríguez Barcia, 2008). Asimismo, algunos estudios han analizado diversos aspectos de ideología en las obras lexicográficas desde una perspectiva diacrónica (Quilis Merín, 2014; Rodríguez Barcia, 2015).

Por otra parte, con independencia de todo tipo de cuestiones ideológicas y atendiendo únicamente a cuestiones lingüísticas, son varios los trabajos donde se estudian los diferentes tipos de unidades fraseológicas y se discute su cabida en el diccionario (Corpas Pastor, 1996; Ruiz Gurillo, 1997). Según Casares (1950), los refranes limitan el terreno lexicográfico por la parte de afuera, mientras que las demás unidades fraseológicas pertenecen de manera más o menos periférica al ámbito lexicográfico. La distinción de Casares, como se explicará más adelante, ha prevalecido en la elaboración del Diccionario académico desde mediados del siglo Xx. Los refranes, concretamente, se estudian hoy como parte de la Paremiología, disciplina en la que intervienen consideraciones folclóricas, etnológicas y antropológicas (Ruiz Gurillo, 1997): se ha señalado, de hecho, la estrecha relación de los refranes con los romances y la cuentística popular (Calero Fernández, 1999).

El objetivo del presente trabajo es analizar el sesgo ideológico en los diccionarios de la Real Academia Española desde 1734hasta 1889, en las entradas correspondientes a las unidades fraseológicas que contienen la palabra mujer, que aparecen dentro del lema mujer. El estudio de la paremiología en los diccionarios es especialmente relevante desde una perspectiva histórica, precisamente porque estas unidades no pertenecen a la lexicografía actual $^{2}$.Se exploran dos problemas interrelacionados: (1) de qué forma el diccionario, como notario, nos ayuda a representarnos una imagen de la ideología hegemónica de los siglos XVIII y XIX a partir de las unidades fraseológicas mismas y (2) en qué medida el diccionario, como legislador, añade "leña lexicográfica al fuego" (Forgas Berdet, 2007: 13).Para abordar el primer problema, se ofrece una tipología formal de las unidades fraseológicas, atendiendo a criterios sintáctico-semánticos: el tipo de rol otorgado a las mujeres en las unidades fraseológicas muestra una determinada representación de lo femenino. Para abordar el segundo, se analizan fenómenos enunciativos en las definiciones de las unidades

\footnotetext{
${ }^{2}$ El tratamiento de otras cuestiones (p. ej., las marcas pragmáticas o el vocabulario sobre oficios) podría considerarse no pertinente desde esa óptica -sería poco riguroso rechazar mujer del alcalde como definición de alcaldesa, si aparece en una época en que esa correspondencia es un fiel reflejo del orden social-. 
fraseológicas, los cuales evidencian la implicación de los académicos en un sentido determinado. A partir del análisis, se comprobará que el sesgo ideológico se observa tanto en las unidades fraseológicas mismas (subentradas del diccionario) como en sus definiciones, elaboradas por los académicos.

\section{Metodología}

Constituyen el corpus de trabajo todas las ediciones del Diccionario académico desde su primera publicación hasta 1889. El primer tomo relevante es el volumen IV del Diccionario de Autoridades, publicado en 1734, correspondiente a la letra $\mathrm{m}$. Se incluyen las ediciones de 1780, 1783, 1791, 1803, un suplemento de 1803, 1817, 1822, 1832, 1837, 1843, 1852, 1869 , $1884,1889^{3}$. Se han recopilado todas las subentradas que contienen la palabra mujer (muger, en las primeras ediciones) y que aparecen en la entrada de mujer (ver Anejo 1, en el que se presenta la colección completa de unidades analizadas).En primer lugar, se ha anotado la presencia de unidades fraseológicas con la palabra mujer en los diccionarios, para trazar su evolución a lo largo de las ediciones. A continuación, se ha realizado una tipología de unidades fraseológicas con la palabra mujer atendiendo a su forma. Por último, se han analizado las definiciones teniendo en cuenta los elementos de subjetividad que en ellas pueden observarse. Para ello, se ha empleado la terminología sobre subjetividad en el lenguaje propuesta por Kerbrat-Orecchioni (1986), especialmente los conceptos de subjetivema y enunciatema.

\section{Análisis}

Este apartado se estructura de la siguiente forma: en la sección 4.1., revisamos brevemente la presencia de unidades fraseológicas con la palabra mujer recogidas en el lema mujer en los Diccionarios académicos que componen el corpus de trabajo; en la sección 4.2., proponemos una caracterización sintáctico-semántica de las unidades fraseológicas con la palabra mujer, dentro del lema mijer, incluidas en todos los diccionarios analizados; en la sección 4.3., analizamos los fenómenos enunciativos en las definiciones de las unidades fraseológicas proporcionadas por los académicos.

\subsection{Evolución de la presencia de unidades fraseológicas en el Diccionario académico}

3Para todos los diccionarios utilizados en la elaboración del trabajo: recurso disponible en línea, http://buscon.rae.es/ntlle/SrvltGUILoginNtlle.

García Ramón, A. (2018). Elementos ideológicos en las unidades fraseológicas con la palabra mujer dentro del lema mujer en el Diccionario académico de los siglosXVIII y XIX .Textos en Proceso 3(2), 144-165 
En 1734, año de la publicación del tomo del Diccionario de autoridades correspondiente a la letra $m$, se incluyen, como subentradas de muger, seis unidades fraseológicas. En el Diccionario académico de 1889 encontramos 59. En todos los casos, son cuantitativamente predominantes los refranes frente a otros tipos de unidades fraseológicas (Figura 1).

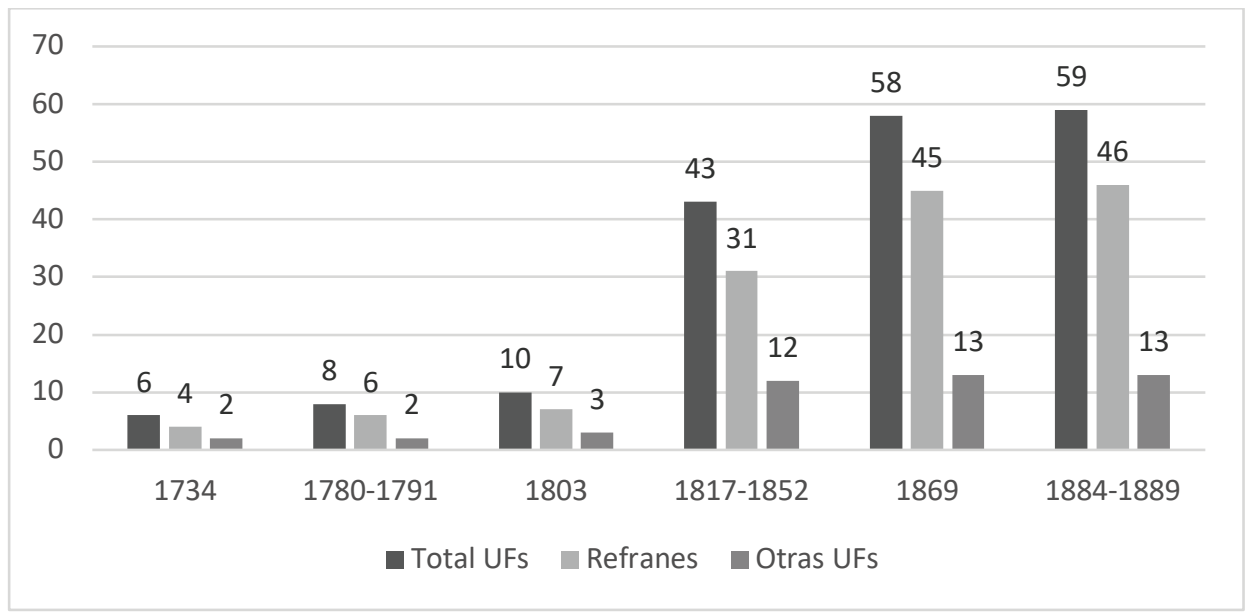

Figura 1. Presencia de unidades fraseológicas con la palabra mujer dentro del lema mujer en el Diccionario académico (siglos XVIII-XIX)

Se produce un salto especialmente relevante en el diccionario de 1817 y los siguientes. En el siglo XVIII, en plena Ilustración, el interés por las fórmulas paremiológicas disminuye, al tiempo que se denuncia la fragilidad del saber proverbial (Calero Fernández, 1999). En su carta sobre la "Falibilidad de los adagios", Feijoo argumenta que

Todo lo que puede significar essa absoluta de todo el Mundo, bien entendida, es, que el Vulgo lo dice assi comunmente. ¿Y qué fuerza debe hacer, que el Vulgo lo diga? ¿Ni que lo digan la mayor, y aun la maxima parte de los hombres que tratamos? (Feijoo, 1781, p. 2)

En el siglo XIX, resurge la apreciación de las fórmulas paremiológicas y las "frases" populares. El hecho no se debe necesariamente al desarrollo de una creencia más férrea en estos “evangelios abreviados", sino, más probablemente, a la revalorización de lo popular y autóctono "en una época en la que rebrotaba el espíritu nacionalista y se volvían los ojos (...) a las raíces del pueblo” (Calero Fernández, 1999, p. 130). Así pues, a lo largo del siglo XIX, se añade una gran cantidad de unidades fraseológicas: desde sus inicios, el Diccionario académico tenía la voluntad de ponderar la "hermosura" y "riqueza" de la lengua castellana, como se aprecia, por ejemplo, en el "Prólogo" del Diccionario de autoridades. Hasta la 
decimonovena edición del Diccionario académico (1970), se han mantenido las fórmulas paremiológicas. En la decisión de suprimir este elemento, tuvo un gran peso la opinión de Julio Casares. Los criterios esta vez no fueron morales, sino puramente lingüísticos:

Nos fundamos, para empezar, en que el refrán no es un hecho expresivo reducible a una equivalencia conceptual unitaria; y en segundo lugar en que tampoco es una combinación verbal cuyos términos hayan adquirido significación especial al fundirse en un bloque (Casares, 1964, p. 45).

En efecto, si los refranes pudieran conmutarse por una unidad, esa unidad no sería semántica, sino pragmática: sería un acto de habla y, muy frecuentemente, un acto de habla directivo. El refrán, según Conca (1987), se puede considerar como un texto completo: tiene coherencia y con frecuencia presenta intertextualidad, es comprendido dentro de una comunidad cultural y condensa la enciclopedia cultural. Aunque, tal como señala Conca, los refranes pueden ser descriptivos o prescriptivos, lo cierto es que las fórmulas paremiológicas aparentemente descriptivas se podrían considerar como actos de habla indirectos (con fuerza ilocutiva directiva), por lo que son, en el fondo, también prescriptivos. Consideremos los siguientes ejemplos ${ }^{4}$ :

(3) A la muger brava dalle la soga larga.

(27) La muger algarera nunca hace larga tela.

Mientras que (3) es un consejo transmitido con un imperativo, podría decirse que (27) tan solo describe una situación. Esta estrategia para la transmisión de mensajes prescriptivos es propia de los refranes: "los miembros de la colectividad (...) tenderán a imitar en sus actitudes a los personajes premiados y rehuirán de los 'usos punibles', en un intento de ser aceptados por la colectividad" (Calero Fernández, 1999: 126).

\subsection{Caracterización sintáctico-semántica de las unidades fraseológicas con la palabra mujer dentro del lema mujer}

Las unidades fraseológicas que aparecen en el Diccionario académico a lo largo de los siglos XVIII y XIX se pueden clasificar atendiendo a criterios sintácticos y semánticos. De hecho, las expresiones idiomáticas muestran una gran cantidad de regularidades (Newmeyer, 1974).

4Para todos los ejemplos mencionados en el cuerpo del texto, la numeración se corresponde con la del ejemplario(Anejo 1). 
Así, las unidades fraseológicas pueden agruparse de forma que se observe, de la manera más esquemática posible, cómo se representa la figura de la mujer en la fraseología y la paremiología.

Siguiendo a Coseriu (1973), se utilizará la clasificación siguiente, basada en el tipo de unidad por el que es conmutable cada UF, puesto que puede dar cuenta de la totalidad de UF que se analizan en este trabajo:

a) Locuciones: unidades equivalentes a oraciones o textos, que constituyen actos de habla en sí mismas (p. ej., los refranes como $A$ la mujer y a la picaza, lo que vieras en la plaza).

b) Sintagmas estereotipados: equivalentes a sintagmas y conmutables entre sí (p. ej. gozar una mujer).

c) Perifrasis léxicas: funcionan como lexemas (p. ej. mujer del arte). Aunque en principio podrían darse en este grupo perífrasis no nominales, son especialmente relevantes en este trabajo aquellas perífrasis léxicas conmutables por sustantivos.

La caracterización lingüística de unidades fraseológicas estudiadas en este trabajo, según la clasificación mencionada, se recoge en la Tabla 1.

En las locuciones en las que el sustantivo mijer aparece coordinado con otro sustantivo o SN(una gran parte del total), se equipara a la mujer con una serie de elementos (fundamentalmente, animales y objetos), de los cuales, se sobreentiende, el término mujer es, de alguna forma, cohipónimo. Aunque no existe un término en la lengua que pudiera funcionar como hiperónimo, se entiende que el concepto que subyace sería «elementos pertenecientes o subordinados al varón» (con la excepción de amigo experto).

Tabla 1. Caracterización lingüística de las unidades fraseológicas

\begin{tabular}{|c|c|c|}
\hline $\begin{array}{l}\text { Tipo de unidad } \\
\text { fraseológica }\end{array}$ & $\begin{array}{l}\text { Estructura sintáctico- } \\
\text { semántica }\end{array}$ & $\begin{array}{l}\text { Ejemplos extraídos de los } \\
\text { diccionarios }\end{array}$ \\
\hline Locuciones $^{5}$ & la mujer $y+$ sustantivo & $\begin{array}{l}\text { la mujer y la picaza, la mujer y la cibera, la } \\
\text { mujery la gallina, la mujer y la mula, la } \\
\text { mujery la camuesa, la mujer y la galga, la } \\
\text { mujery la sardina, la mujer y el asno, la } \\
\text { mujery la pera, la mujer y el vino, la mujery } \\
\text { el vidrio, la mujery la tela, la mujer y el }\end{array}$ \\
\hline
\end{tabular}

${ }^{5}$ Por cuestiones de espacio, los ejemplos incluidos en el apartado de locuciones en la Tabla 1 no constituyen locuciones completas, sino las partes de esas locuciones que resultan relevantes para la caracterización sintáctico-semántica propuesta aquí. Se pueden consultar las locuciones completas en el Anejo I. 


\begin{tabular}{|c|c|c|}
\hline & & $\begin{array}{l}\text { dinero, la mujery la viña, mujery amigo } \\
\text { experto }\end{array}$ \\
\hline & la mujer + adjetivo & $\begin{array}{l}\text { mujer brava, mujer mala, mujer algarera, } \\
\text { mujer artera, mujer loca, mujer que poco bila, } \\
\text { mujer placera, mujer casada, mujer casta, } \\
\text { mujer honrada, mujer parida, mujer buena, } \\
\text { mujer rogada, mujer barbuda, mujer } \\
\text { compuesta, mujer pulida }\end{array}$ \\
\hline & $\begin{array}{l}\text { mujer de }+ \text { sustantivo } \\
\text { masculino }\end{array}$ & $\begin{array}{l}\text { mujer del escudero, mujer del viñadero, mujer } \\
\text { del ciego, mujer del otro }\end{array}$ \\
\hline \multirow[t]{2}{*}{$\begin{array}{l}\text { Sintagmas } \\
\text { estereotipados }\end{array}$} & verbo + SN con mujer & $\begin{array}{l}\text { ser mujer, echarse con alguna mujer, gozar } \\
\text { una mujer }\end{array}$ \\
\hline & mujer + SPrep o adjetivo & $\begin{array}{l}\text { mujer de su casa, mujer de gobierno, mujer de } \\
\text { punto, mujer fácil }\end{array}$ \\
\hline Perífrasis léxicas & equivalentes a ramera & $\begin{array}{l}\text { mujer pública, mujer de mala vida, mujer de } \\
\text { vida airada, mujer del partido, mujer } \\
\text { mundana, mujer perdida }\end{array}$ \\
\hline
\end{tabular}

Con la categoría mujer + adjetivo, se establece una tipologización basada en modelos de mujer, de los cuales algunos son punibles (A la mijer barbuda de lejos la saluda) y otros premiados (La mujer casada en el monte es albergada). El grupo mujer de + sustantivo masculino sugiere que gran parte de la identidad de la mujer procede de la ocupación o las cualidades del marido, o que la bonanza del marido se ve en el estatus que es capaz de dar a la mujer (La mujer del viñadero, buen otoño y mal invierno).

Se pueden distinguir dos grandes grupos dentro de los sintagmas estereotipados: (1) los sintagmas verbales expresan acciones siempre relacionadas con el ámbito sexual, amoroso o reproductivo (ser mijer, echarse con alguna mujer, gozar mujer, tomar mujer); y (2) los sintagmas nominales diferencian varios tipos de mujer según su ocupación (mujer de gobierno) o según su mayor o menor correspondencia con el modelo deseable de mujer (mujer de su casa, mujer de punto, mujer fácið).

Por último, las perífrasis léxicas (mujer pública, de vida airada, del arte, etc.) equivalen todas a la voz ramera. En ocasiones, se añaden a la definición elementos valorativos más allá de las connotaciones del término. Se verá esta cuestión más detenidamente al hablar de cómo emerge la ideología en las definiciones propuestas por los académicos.

\subsection{El contenido ideológico en las definiciones: fenómenos enunciativos en el discurso de los académicos}

${ }^{6}$ Esta perífrasis no significa aquí 'mujer propensa a mantener relaciones sexuales', sino 'la que es conocidamente frágil'. 
Un diccionario debe recoger las palabras que usa la comunidad lingüística (...). Digo esto para no caer en el viejo tópico de acusar al diccionario, sobre todo al académico, de tener 'defectos o vicios' impropios de una sociedad avanzada, como las acusaciones de machismo (...). Por eso la principal crítica que en todo caso se le puede hacer a un diccionario es que sus definiciones no se correspondan con el uso que los hablantes dan a esas palabras (Ariza, 2008, p. 32).

Las palabras de Ariza no requieren explicación: es evidente a qué tipo de reivindicación contestan. Sin embargo, existe otra visión del hecho lexicográfico, según la cual, aunque un requisito de la definición es que no debe traslucir ninguna ideología, lo cierto es que "el diccionario es todo menos una obra neutral, por lo que al lexicógrafo solo le queda paliar, al menos en parte, esta falta de objetividad" (Medina Guerra, 2003: 134; ver también, sobre el problema de la objetividad en las obras lexicográficas, Forgas Berdet, 2015). En este apartado, se discutirá quiénes podrían serlos actantes dentro del proceso comunicativo y cómo se introducen elementos valorativos en las definiciones, tomando como base la terminología de Kerbrat-Orecchioni (1986), especialmente las nociones de enunciatema y subjetivema.

\subsubsection{Los actantes del diccionario: los enunciatemas}

"Benveniste lo repite incansablemente: el 'yo' del código pertenece a todo el mundo; pero hablar es apropiárselo (...); todo acto de habla es egocéntrico" (Kerbrat-Orecchioni, 1986, p. 72). Se produce en todo acto comunicativo una identificación de interlocutores. En este trabajo, no se discutirá tal identificación en el nivel extratextual, del emisor y el receptor reales -tendría que realizarse un estudio histórico sobre la recepción del diccionario para llegar a tales conclusiones-, sino en el nivel intratextual, el del enunciador y el enunciatario (Forgas Berdet, 2007).

Kerbrat-Orecchioni distingue varios tipos de elementos deícticos que, según su lingüistica de la enunciación, no se identifican atendiendo a criterios estrictamente formales -es decir, lo que formalmente llamaríamos deixis-, sino más bien teniendo en cuenta cómo se percibe a través de ellos "la manera (enteramente subjetiva) en que el hablante enfoca el proceso" (1986, p. 60). De los tipos de referencia que distingue Kerbrat-Orecchioni absoluta, relativa al contexto lingüístico y relativa a la situación de comunicación- interesa especialmente, para el propósito de este trabajo, el último grupo. De hecho, la autora considera que esta referencia es la propiamente deíctica. 
Con respecto a los pronombres personales, la lingüística de la enunciación explica que frecuentemente, en los diccionarios, se emplea la primera persona del plural con valor impersonal, sustituible por se (Forgas Berdet y Herrera Rodrigo, 2000). Tanto nos como se tienen aquí valor universal: en teoría, no se refieren a ningún grupo. Pero en el Diccionario académico de los siglos XVIII y XIX, la impersonalización se identifica, en realidad, con el lector varón (esto es, el lector no marcado o normal). Así, en las definiciones, la presuposición es que todos los consejos, si no se especifica lo contrario, van dirigidos a un lector masculino, representado mediante la partícula se:

(3) A la muger brava Dalle la soga larga. Refr. que aconseja se disimule con prudencia lo que no se puede remediar prontamente, aguardando ocasión y coyuntura à propósito, para reprehenderlo o castigarlo.

(7) CON LAS Muger y EL Dinero NO TE BurLes COMPAÑERO. ref. que enseña el recato y cuidado con que se debe atender y gobernar uno y otro.

En contraposición, tanto las mujeres como los personajes varones marcados por alguna característica específica (es decir, los varones no estándar) se representan mediante pronombres, determinantes o sintagmas que pertenecen a la tercera persona:

(2) Ser MUger. Phrase con que se explica haber llegado una moza à estado de menstruar.

(39) LA MUGER y LA SARDinA DE ROSTROS EN LA CENIZA. ref. que advierte álas mugeres la aplicacion que deben tener á las ocupaciones domésticas propias suyas.

Se dan, sin embargo, algunas excepciones en que el personaje femenino sirve para ilustrar cuestiones relativas al ser humano:

(5) A la muger mala, POCO LE APROVECHA GUARDA. Refr. que enseña, que al que es de mala inclinación, y esta habituado en vicios y ruindades, por mas diligencias que se hagan, es dificultoso sacarle de ellos.

\subsubsection{La valoración: los subjetivemas}

Un subjetivema es una palabra o enlace extraoracional (p. ej. implicaturas a partir de sin embargo) con notable carga afectiva o evaluativa. En el caso de las definiciones de las unidades fraseológicas consideradas aquí, es de gran relevancia el verbo que establece cómo 
ha de interpretarse la relación del refrán con el mundo. Por un lado, (1) encontramos la enseñanza de los refranes, presente habitualmente en la oración subordinada introducida por que $e^{7}$. Por otro lado, (2) se distinguen diferentes niveles de credibilidad de los refranes: esta es una fuente más interesante de análisis. Por tanto, se dan dos planos, de los cuales el segundo se encarga de dar mayor o menor fuerza epistémica al primero.

Kerbrat-Orecchioni explica que la subjetividad es una cuestión de grado: mientras que algunos refranes enseñan que... ( $+>$ la enseñanza del refrán es verdadera) otros dan a entender que... (+> la enseñanza del refrán puede ser verdadera). Muy esquemáticamente, esta escala puede servir para representar los diferentes grados de compromiso del enunciador con lo enunciado. Una unidad fraseológica ${ }^{8}$

$-$

da a entender (4), significa (22), alude (57), expresa (50), explica (6), con que se denota (36), denota (23), indica (18), enseña (5)

Paralelamente, se dan otras escalas verbales, con que se otorga mayor o menor intensidad semántica a la valoración positiva o negativa de una determinada acción. Paradójicamente, como se hace explícito que se trata de una valoración, podría considerarse que estos enunciados son menos tendenciosos. El contenido subjetivo se hace patente y, así, de algún modo, los verbos evaluativos funcionan como marcas pragmáticas. Así, se dice que una unidad fraseológica:

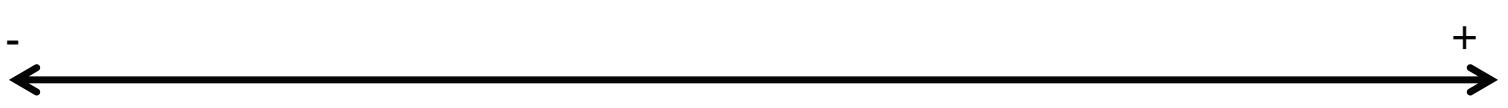

amonesta (52), acusa (48), censura (54), reprende (34), vitupera (30)

Sean más o menos precisas estas escalas, es relevante señalar que existen diversos grados de implicación subjetiva, que además se mueven en ejes diferentes: por una parte, una escala de compromiso epistémico y, por otra, una escala de valoración positiva o negativa (ver, a este respecto, Rodríguez Barcia, 2012). Un ejemplo de la tendencia a la mayor objetividad en el Diccionario académico podría verse en el paso del primer al segundo eje en la evolución de la definición de a la mujer y a la picaza, lo que vieras en la plaza: mientras que en el año 1734 (6) se dice que el refrán explica una enseñanza, en 1852 (48) se dice que

\footnotetext{
${ }^{7}$ Estas enseñanzas se considerarían, en general, sexistas desde la óptica actual y, por tanto, no admiten tantos matices interpretativos; se podría decir que no son fruto de la subjetividad del diccionario sino del uso general de los hablantes.

${ }^{8}$ Los números distribuidos en las escalas se refieren al número asignado a cada UF en el Anejo 1. 
el refrán acusa a las mujeres de poco aptas para guardar secretos. En realidad, consideramos que la segunda de las definiciones es menos subjetiva, puesto que asume la propia subjetividad del refrán.

Abundan en las definiciones las perífrasis verbales de obligación:

(7) CON LA MUger y EL DiNERO NO TE BURLES COMPAÑERO. ref. que enseña el recato y cuidado con que se debe atender y gobernar uno y otro.

(8) LA MUGER Y LA CIBERA NO LA CATES Á LA CANDELA: otros dicen LA MUGER Y LA TELA. ref. que enseña la precaucion con que se han de escoger estas cosas para no quedar engañado.

La subjetividad no emerge solo en las propias perífrasis, sino en la sintaxis de las definiciones, la cual restringe la interpretación del enunciado: la interpretación preferida en la precaución con que se han de escoger es que, efectivamente, se han de escoger de esa forma, independientemente de que lo muestre o no el refrán. Serían algo diferentes las posibilidades interpretativas si la construcción enseña el cuidado con que se debe atender se sustituyera por enseña que se debe atender con cuidado, puesto que la primera posibilidad presupone un conocimiento a priori. Rasgos como estos logran que el Diccionario aparezca, en muchos casos, como un verdadero código de comportamiento.

En cuanto a los sustantivos, encontramos dos campos asociativos muy fructíferos en la valoración moral de la mujer: el relativo a su recato y el relativo al peligro que corre. Ambos rasgos son inversamente proporcionales. Así, aparece con frecuencia honestidad junto a recato $(29,61)$, o vicios junto a peligros (59). También los adjetivos participan de esta distinción: existe la mujer recatada y pundonorosa (14), buena madre de familia (55), frente a la casquivana y lasciva (52).

Una marca de subjetividad muy recurrente se encuentra en los cuantificadores indeterminados evaluativos, los cuales sugieren que existen unas pautas de comportamiento estables y cuantificables: el demasiado adorno de las mujeres (30), el afán inmoderado de divertirse (54), las mijeres que paran poco en casa (59), cuando se reínen muchas mujeres, suele bablarse mucho y con poco respeto a la verdad (68).

Finalmente, ciertos adverbios destacan la veracidad de enunciados o descripciones: la mujer fácil se describe como la que es conocidamente frágil (15), de lo cual se comprende que la fragilidad es una cualidad intrínseca de esa mujer y no una valoración subjetiva. En (19), se aconseja que se huya de las mujeres que tienen barbas, por ser regularmente de mala condición. El adverbio destaca aquí el carácter enciclopédico (la base experiencial) de la apreciación. 
Sin embargo, observamos en el Diccionario académico un progresivo movimiento hacia la objetividad o, al menos, hacia la menor presencia de subjetivemas. Por ejemplo, en 1822 se modifican todas las definiciones de las perífrasis léxicas equivalentes a ramera aunque cabe notar la enorme carga evaluativa que tiene la palabra en sí-. La definición de mujer de la mala vida o de la vida airada es, en 1817:

(11) Muger de LA MALA VIDA Ó DE LA VIDA AIRADA. La viciosa y entregada a la vida licenciosa.

En cambio, en la edición de 1822, leemos:

(44) Muger de la MALA VIDA Ó DE LA VIDA AIRADA. Ramera.

\section{Conclusión}

Frente a otros tipos de escrito con receptores más definidos, podríamos decir que los diccionarios generales de la lengua

abarcan o pretenden abarcar como receptora a la práctica totalidad de las áreas y estamentos sociales; tienen, en definitiva, una pretensión de universalidad que en el campo de la cortesía lingǘstica les obliga más que a los otros a afinar sus instrumentos al máximo a fin de que ninguno de los colectivos a los que se dirijan pueda verse menoscabado (Forgas Berdet, 2004, p. 5).

El fragmento de Forgas Berdet hace referencia a los diccionarios contemporáneos. Los diccionarios que nos ocupan en este trabajo comparten con las obras lexicográficas de hoy esa pretensión de universalidad. Quizás difieren, en cambio, en la destreza con que son capaces de alcanzar esa universalidad, al menos si son observados desde una perspectiva actual.

A través del análisis de las estrategias discursivas en las definiciones de las unidades fraseológicas con la voz mujer, hemos podido comprobar el sesgo ideológico de la obra: gran parte de esa tendenciosidad corresponde, en realidad, a una elección restringida de los receptores: "Es sabido que un texto escrito (...) preselecciona de alguna manera a sus receptores y gracias a ello se estructura en base a unas estrategias específicas (...) dirigidas a este lector o lectora ideal" (Forgas Berdet, 2007). Se podría considerar que, en el Diccionario académico, el receptor ideal es varón (Calero Fernández, 1999). Por tanto, las definiciones se basan, de alguna forma, en la ocultación de los demás grupos. 
Sin embargo, es problemático hablar de "sexismo" o de "discriminación", tal como entendemos hoy esos términos, en las obras académicas de los siglos XVIII y XIX. Más bien, podría considerarse que la cortesía hacia las mujeres, simplemente, no se activa en las obras lexicográficas tratadas en este trabajo - ni en su forma positiva, ni en su forma negativa-: no se percibe en los enunciados una identificación con la mujer, lo cual indica que no es la lectora ideal, pese a que en muchos casos sí pudiera ser la lectora real del texto. La ideología de los académicos, representada en las definiciones, coincide en gran medida con la de las enseñanzas contenidas en las unidades fraseológicas y, por tanto, el diccionario no contiene, estrictamente, dos discursos -aquí, como sinónimo de ideologías-, sino solo uno, materializado en dos planos discursivos -uno testimonial, otro normativo-diferentes.

\section{Referencias}

Ariza, Manuel (2008).Insulte usted sabiendo lo que dice y otros estudios sobre el léxico. Madrid: Arco Libros.

Blecua Perdices, José Manuel (1990)."Diccionario y enunciación”. En Jornadas de Filología. Homenaje al Profesor Francisco Marsá, Barcelona: Universidad, 61-74.

Calero Fernández, M. ${ }^{a}$ Ángeles (1999).Sexismo lingüístico. Análisis y propuestas ante la discriminación sexual en el lenguaje. Madrid: Narcea.

Casares, Julio (1964). "La frase proverbial y el refrán”, Revista Universidad Pontificia Bolivariana, 27 (95): 36-49.

Castillo Carballo, M. a Auxiliadora (2003)."La macroestructura del diccionario”. En Medina Guerra, Antonia M. ${ }^{a}$ (ed.), Lexicografía española, Barcelona: Ariel, 79-102.

Conca, Maria (1987).Paremiologia. Valencia: Servei de Publicacions de la Universitat de València.

Corpas Pastor, Gloria (1996). Manual de fraseología española. Madrid: Gredos.

Coseriu, Eugenio (1973). Teoría del lenguaje y lingüística general. Madrid: Gredos.

Coseriu, Eugenio (1986 [1964]). "Introducción al estudio estructural del léxico". En Coseriu, Eugenio, Principios de semántica estructural, Madrid: Gredos.

Forgas Berdet, Esther (1999). "La (de)construcción de lo femenino en el diccionario". En Fernández de la Torre Madueño, María Dolores; Antonia María Medina Guerra y Lidia Taillefer de Haya (eds.), El sexismo en el lenguaje, II, Málaga: Centro de Ediciones de la Diputación Provincial de Málaga, 577-590 [Disponible en línea: http://www.urv.cat/dfilrom/publicacions/2c89109d.pdf].

Forgas Berdet, Esther (2004)."Diccionario, cortesía lingüística y norma social”. En Bravo, Diana y Antonio Briz (eds.), Pragmática sociocultural: estudios sobre el discurso de cortesía en español, Barcelona: Ariel, 341-356 Disponible en línea en: www.urv.cat/dfilrom/publicacions/ecb9fe2f.pdf].

Forgas Berdet, Esther (2007). “Diccionarios e ideologías”. Interlingüística 17: 2-16. [Disponible en línea en: https://dialnet.unirioja.es/descarga/articulo/2316343.pdf].

Forgas Berdet, Esther (2015). "La (im)posible objetividad de la práctica lexicográfica”. En Serrano Dolader, David; Porroche Ballesteros, Margarita y María Antonia Martín 
Zorraquino (eds.), Aspectos de la subjetividad en el lenguaje, Zaragoza: Institución Fernando el Católico, 99-118.

Forgas Berdet, Esther y María Herrera Rodrigo (2000). "Diccionario y discurso: la emergencia de los fenómenos enunciativos (1)". En Bustos Tovar, José Jesús et al. (eds.), Lengua, discurso, texto, Madrid: Visor, 1035-1048 [Disponible en línea en: www.urv.cat/dfilrom/publicacions/194cf6c2.pdf].

Feijoo y Montenegro, Benito Gerónimo (1781). "Falibilidad de los adagios". En su Cartas eruditas y curiosas, Madrid: Real Academia de Derecho Español y Público, 1-12.

Kerbrat-Orecchioni, Catherine (1986). La enunciación. De la subjetividad en el lenguaje (trad. de Gladys Anfora y Emma Gregores). Buenos Aires: Hachette.

Lledó Cunill, Eulalia (coord.), M. ${ }^{a}$ Ángeles Calero Fernández y Esther Forgas Berdet (2004).De mujeres y diccionarios. Evolución de lo femenino en la22. ${ }^{a}$ edición del DRAE, Madrid: Instituto de la Mujer (Ministerio de Trabajo y Asuntos Sociales).

Medina Guerra, Antonia M. (2003)."La microestructura del diccionario: la definición”. En Medina Guerra, Antonia M. ${ }^{a}$ (coord.), Lexicografía española, Barcelona: Ariel, 127150.

Newmeyer, Frederick J. (1974). “The Regularity of Idiom Behavior”, Lingua, 34: 327-342.

QuilisMerín, Mercedes (2014). "Ideología en el Diccionario Nacional (1846-47) de Ramón Joaquín Domínguez: La "nomenclatura vergonzante"”, Boletín hispánico helvético,23: 141-164.

Real Academia Española (1726-1739). [Diccionario de autoridades]Diccionario de la lengua castellana, en que se explica el verdadero sentido de las voces, su naturaleza y calidad, con las phrases o modos de hablar, los proverbios o refranes, y otras cosas convenientes al uso de la lengua, Madrid, Francisco del Hierro.

Real Academia Española (1780). Diccionario de la lengua castellana, Madrid, Juan Ibarra.

Real Academia Española (1783). Diccionario de la lengua castellana, Madrid, Juan Ibarra.

Real Academia Española (1791). Diccionario de la lengua castellana, Madrid, Vda. De Ibarra.

Real Academia Española (1803). Diccionario de la lengua castellana, Madrid, Vda. De Ibarra.

Real Academia Española (1817). Diccionario de la lengua castellana, Madrid, Imprenta Real.

Real Academia Española (1822). Diccionario de la lengua castellana, Madrid, Imprenta Nacional.

Real Academia Española (1832). Diccionario de la lengua castellana, Madrid, Imprenta Real.

Real Academia Española (1837). Diccionario de la lengua castellana, Madrid, Imprenta Nacional.

Real Academia Española (1843). Diccionario de la lengua castellana, Madrid, Francisco María Fernández.

Real Academia Española (1852). Diccionario de la lengua castellana, Madrid, Imprenta Nacional.

Real Academia Española (1869). Diccionario de la lengua castellana, Madrid, M. Rivadeneyra.

Real Academia Española (1884). Diccionario de la lengua castellana, Madrid, Gregorio Hernando.

Real Academia Española (1889). Diccionario de la lengua castellana, Madrid, Hernando y Compañía.

Rodríguez Barcia, Susana (2008). La realidad relativa: La realidad relativa. Evolución ideológica en el trabajo lexicográfico de la Real Academia Española (1726-2006). Vigo: Universidad de Vigo.

Rodríguez Barcia, Susana (2012). "El análisis ideológico del discurso lexicográfico: una propuesta metodológica aplicada a diccionarios monolingües del español", Verba, 39: 135-159. 
Rodríguez Barcia, Susana y Fernando Ramallo (2015). "De masones, sodomitas, herejes y comunistas: las minorías en la historia de la lexicografía monolingüe española", Estudios de Lingüistica del Español, 36: 449-483.

Ruhstaller, Stefan (2003). "Las obras lexicográficas de la Academia”. En Medina Guerra,

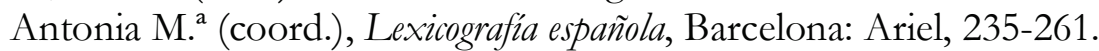

Ruiz Gurillo, Leonor (1997). Aspectos de fraseología teórica española. Valencia: Universitat.

Senz, Silvia y Montserrat Alberte (eds.) (2011). El dardo en la Academia. Santa Cruz de Tenerife: Melusina.

Zamora Vicente, Alonso (1999). "Las mujeres en la Academia". En Historia de la Real Academia Española, Madrid: Espasa Calpe.

Amparo García Ramón es doctoranda en el Departamento de Filología Española de la Universitat de València. Forma parte del grupo de investigación Val.Es.Co. y del proyecto de investigación Es.Vag.Atenuación. Su investigación se centra en el análisis del discurso, especialmente en el análisis de estructuras propias de la interacción y estrategias de negociación interaccional relacionadas con la gestión de asimetrías epistémicas. 
Anejo 1. Unidades fraseológicas con la palabra mujer dentro del lema mujer en los diccionarios académicos de los siglos XVIII y XIX

1734

(1) MugER DE SU CASA. La que tiene gobierno y disposición para mandar y executar las cosas que la pertenecen, y cuida de su hacienda y familia con mucha exacción y diligencia.

(2) SER MUGER. Phrase con que se explica haber llegado una moza à estado de menstruar.

(3) A LA MUGER BRAVA DALle la SOGA LARGA. Refr. que aconseja se disimule con prudencia lo que no se puede remediar prontamente, aguardando ocasión y coyuntura à propósito, para reprehenderlo o castigarlo.

(4) A LA MUGER CASADA, EL MARIDO LE BASTA. Refr. que da à entender que no debe la buena muger dar gusto sino a su marido.

(5) A LA MUger mala, POCO LE APROVECHA GUARDA. Refr. que enseña, que al que es de mala inclinación, y esta habituado en vicios y ruindades, por mas diligencias que se hagan, es dificultoso sacarle de ellos.

(6) A LA MUGER y A LA PICAZA, LO QUE VIERAS EN LA PLAZA. Refr. que explica la prudencia y consideracioncon que se deben revelar los secretos y cosas de importancia, por el peligro de que los publiquen.

1780. Se añaden las siguientes unidades fraseológicas:

(7) CON LAS MUGER Y EL DINERO NO TE BURLES COMPAÑERO. ref. que enseña el recato y cuidado con que se debe atender y gobernar uno y otro.

(8) LA MUGER Y LA CIBERA NO LA CATES Á LA CANDELA: otros dicen LA MUGER Y LA TELA. ref. que enseña la precaucion con que se han de escoger estas cosas para no quedar engañado.

1783, 1791: no hay cambios en la inclusión o exclusión de unidades fraseológicas

1803. Se añade la siguiente unidad fraseológica:

(9) LA MUGER Y LA GALLINA HASTA LA CASA DE LA VECINA, Ó POR ANDAR SE PIERDEN AHINA. ref. que advierte á las mugeres los riesgos á que se exponen por no estar recogidas en su casa.

1803, suplemento. Se añade la siguiente unidad fraseológica:

(10) MUGER PÚBLICA. La prostituta ó ramera.

1817. Se añaden las siguientes unidades fraseológicas:

(11) Muger de la mala VIDA Ó DE LA VIDA AIRADA. La viciosa y entregada a la vida licenciosa.

(12) MUGER DEL PARTIDO. Lo mismo que ramera. 
(13) Muger DE GOBIERNO. La criada que tiene á su cargo el gobierno económico de la casa.

(14) Muger DE PUNTO. La que es recatada y pundonorosa.

(15) MUGER FÁCIL. La que es conocidamente frágil.

(16) Muger mundana. La pública.

(17) MUger PERDIDA. La ramera, viciosa, prostituta y de mal vivir.

(18) Á LA MUGER BAILAR Y AL ASNO REBUZNAR, EL DIABLO SE LO DEBIÓ DE MOSTRAR. ref. que indica la natural inclinación y disposición que tienen las mugeres a bailar.

(19) Á LA MUger BARBUda DE LEJOS LA SALUDA. ref. que aconseja se huya de las mujeres que tienen barbas, por ser regularmente de mala condicion.

(20) Á LA MUGER CASTA Dios LE BASTA. ref. que enseña que Dios cuida particularmente de las mujeres honestas. (buscar honesta)

(21) Á LA MUGER Y Á LA VIÑA EL HOMBRE LA HACE GARRIDA. ref. que da a entender que en la galanura y buen porte de la muger se conoce la estimacion que hace de ella su marido, asi como se conoce en la lozania de la viña el cuidado de su amo.

(22) Á LA MUGER Y A LA MULA POR EL PICO LES ENTRA LA HERMOSURA. ref. que significa que la conveniencia se manifiesta exteriormente en la hermosura y brio.

(23) COMPUESTA NO HAY MUGER FEA. ref. que denota que el aseo y compostura encubren la fealdad.

(24) DE TU MUgER Y DE TU AMIGO EXPERTO, NO CREAS SINO LO QUE SUPIERES DE CIERTO. ref. que enseña que no todo lo que se dice ú oye se debe creer, aunque se tenga buen concepto de quien lo dice, porque es fácil padecer equivocacionó engaño.

(25) ECHARSE CON ALGUNA MUGER. f. ant. Conocerla carnalmente.

(26) GOZAR UNA MUGER. f. Tener acto carnal con ella.

(27) LA MUGER ALGARERA NUNCA HACE LARGA TELA. ref. que advierte que la muger que habla mucho trabaja poco.

(28) LA MUGER ARTERA EL MARIDO POR DELANTERA. ref. que enseña que la muger sagaz se excusa con su marido para dejar de hacer lo que no la conviene.

(29) LA MUGER CASADA EN EL MONTE ES ALBERGADA. ref. en que se advierte que la muger casada que tiene la honestidad y recato correspondiente á su estado, se hospeda y recoge seguramente en cualquiera parte.

(30) LA MUGER DEL CIEGO PARA QUIEN SE AFEITA? ref. que vitupera el demasiado adorno de las mugeres con el fin de agradar á otros que á sus maridos.

(31) LA MUGER DEL ESCUDERO GRANDE BOLSA Y POCO DINERO. ref. contra los que ostentan mas de lo que pueden. 
(32) LA MUGER DEL VIÑADERO BUEN OTOÑO Y MAL INVIERNO. ref. que da a entender que la subsistencia de las mugeres depende comúnmente del oficio u ocupacion de sus maridos, como sucede á la del que guarda viñas.

(33) LA MUGER HONRADA LA PIERNA QUEBRADA Y EN CASA. ref. que aconseja el recato y recogimiento que deben observar las mugeres.

(34) LA MUGER LOCA POR LA VISTA COMPRA LA TOCA. ref. que reprende la ligereza é indiscrecion de los que entran en negocios sin examinar sus circunstancias.

(35) LA MUGER QUE POCO HILA SIEMPRE TRAE MALA CAMISA. ref. que advierte que no medra el que trabaja poco.

(36) LA MUGER Y LA CAMUESA POR SU MAL SE AFEITAN. ref. con que se denota que los afeites en las mujeres comunmente se usan para encubrir ó disimular sus defectos, aludiendo á la camuesa, que cuando está mas colorada y parece mejor, suele hallarse podrida por dentro.

(37) LA MUGer y LA GALGA EN LA MANGA. Dicho festivo a favor de las mugeres pequeñas.

(38) LA MUGER Y LA PERA LA QUE CALLA ES BUENA. ref. que recomienda el silencio á las mugeres.

(39) LA MUGER Y LA SARDINA DE ROSTROS EN LA CENIZA. ref. que advierte á las mugeres la aplicacion que deben tener á las ocupaciones domésticas propias suyas.

(40) LA PRIMERA MUGER ESCOBA, Y LA SEGUNDA SEÑORA. ref. que enseña que suelen los que se casan dos veces tratar mejor a la segunda muger que a la primera.

(41) MuÉSTRAMe TU MUger, DECIRTE HE QuÉ MARIDO TIEN. ref. que da a entender que en el porte de los inferiores se conoce el gobierno del superior.

(42) QUiEn MAS NO PUEDE CON SU MUGER SE ACUESTA. ref. que se dice de aquellos que se contentan con lo lícito mas por necesidad que por virtud.

(43) TOMAR MUGER. f. Casarse ó contraer matrimonio con ella.

1822: modificaciones en las definiciones

(44) Muger de la mala Vida Ó DE LA VIDA AIRADA. Ramera.

(45) Muger Del Partido. Ramera.

(46) Muger mundana. Ramera.

(47) MUGER PERDIDA. Ramera.

$1832,1837,1843$ : no hay cambios

1852. Cambia la definición:

García Ramón, A. (2018). Elementos ideológicos en las unidades fraseológicas con la palabra mujer dentro del lema mujer en el Diccionario académico de los siglosXVIII y XIX .Textos en Proceso 3(2), 144-165 
(48) A LA MUJER Y A LA PICAZA, LO QUE VIERAS EN LA PLAZA. ref. que acusa a las mujeres de poco aptas para guardar secretos.

1869. Se añaden las siguientes unidades fraseológica:

(49) MUJER DEL ARTE. fam . Ramera

(50) Á MUJER PARIDA Y TELA URDIDA, NUNCA LE FALTA GUARIDA. ref. que expresa que así acontece á la primera, por consideracion; con la segunda porque donde quiera es util.

(51) Ni BEBER DE BRUCES, NI MUJER DE MUCHAS CRUCES. ref. que advierte los peligros de las que son mojigatas.

(52) NI POR CASA NI POR VIÑA, NO TOMES MUJER JIMIA. ref. que amonesta que por razon de intereses no hay que casarse nunca con la mujer casquivana ó lasciva.

(53) MUjer, VIENTO y VENTURA, PRONTO SE MUDAN. ref. que indica la inestabilidad de estas tres cosas.

(54) Á LA MUJER LOCA, MÁs LE AgRADA EL PANDERO QUE LA TOCA. ref. que censura en la mujer el afan inmoderado de divertirse.

(55) LA MUjer BUENA, DE LA CASA VACÍA HACE LLENA. ref. que denota, por lo que hace prosperar la casa, el órden y la economía de la buena madre de familia.

(56) Mujer COMPUesta Quita Al MARIDO DE LA OtRA PUERTA. ref. que recomienda á la mujer el aseo y aliño moderado.

(57) LA MUJER PULIDA, LA CASA SUCIA Y LA PUERTA BARRIDA. ref. que alude al descuido con que suelen mirar sus casas las mujeres muy dadas á componerse.

(58) LA MUJER ROGADA, Y LA OLLA REPOSADA. ref. que enseña cuanto realza á la mujer el recato.

(59) LA MUjER PLACERA DiCE DE TODOS Y TODOS DE ELLA. ref. que expresa los vicios y peligros de las mujeres que paran poco en casa.

(60) NI MULA CON TACHA, NI MUJER SIN RAZA. ref. que advierte la ventaja de que la mujer venga de buena madre, y que lo sean si es posible, todas las de su familia.

(61) LA MUJER Y EL VIDRIO SIEMPRE ESTAN EN PELIGRO. ref. para ponderar el cuidado que la mujer ha de tener de su honestidad y recato.

(62) LA MUJER Y EL VINO, SACAN AL HOMBRE DE TINO. ref. que encarece la necesidad de no dejarse dominar por la liviandad y la embriaguez.

(63) Ni MUjER DE OTRO, NI COCES DE POTRO. ref. que advierte los peligros de tener trato con mujer ajena. 
1884. Se añade un refrán y cambian cuatro definiciones:

(64) LA MUJER DEL VIÑADERO, BUEN OTOÑO Y MAL INVIERNO. ref. que da a entender que como la subsistencia de las mujeres depende comunmente del oficio u ocupación de sus maridos, lo pasa bien la del viñadero en la época en la que este gana.

(65) LA MUJER Y LA CAMUESA, Ó LA CEREZA, POR SU MAL SE AFEITAN. ref. que advierte que se hacen víctimas del apetito, la primera por los afeites y adorno de su rostro, y la segunda por los colores que indican su madurez.

(66) LA MUJER Y LA GALGA, EN LA MANGA. ref. que elogia festivamente á la mujer pequeña.

(67) LA MUJER Y LA PERA, LA QUE CALLA ES BUENA, Ó LA QUE NO SUENA. ref. que alaba el silencio en las mujeres.

(68) YeNDO LAS MUjERES AL HILANDERO, VAN AL MENTIDERO. ref. que advierte que, cuando se reunen muchas mujeres, suele hablarse mucho y con poco respeto a la verdad.

1889: no hay cambios 